UDC 340.13

LBC 67.0

\title{
GRAMMAR RULES FOR DETERMINING A SET OF FACTS WHEN BUILDING ATTRIBUTIVE-NOMINATIVE WORD COMBINATIONS
}

\author{
Sergey B. Polyakov \\ Perm State National Research University, Perm, Russian Federation \\ Anastasia V. Bogdanova \\ Perm State National Research University, Perm, Russian Federation
}

Introduction: when determining the sets of facts of the law, the legislator uses different structures. In the legal practice there appear the problems related to the ambiguity of grammatical structures in the legislative activity and (or) to understanding correct grammatical structures by law enforcers.

Hence, the aim of the legal science is the analysis of grammatical structures which are necessary for the clear determination of the rules of law and the rules for their use in the solution of specific cases.

Results: the authors present the models of attributive-nominative phrases used by the legislator to determine a set of facts and formulate the rules for their application in the implementation of the law. structure.

Key words: a set of facts, attributive-nominative phrases, lexical level, grammatical level, lexical-grammatical

УДК 340.13

ББК 67.0

\section{ГРАММАТИЧЕСКИЕ ПРАВИЛА ОПРЕДЕЛЕНИЯ ФАКТИЧЕСКОГО СОСТАВА ПРИ КОНСТРУКЦИИ АТРИБУТИВНО-НОМИНАТИВНЫХ СЛОВОСОЧЕТАНИЙ}

\author{
Сергей Борисович Поляков
}

Пермский государственный научно-исследовательский университет, г. Пермь, Российская Федерация

\section{Анастасия Владиславовна Богданова}

Пермский государственный научно-исследовательский университет, г. Пермь, Российская Федерация

Введение: при определении фактических составов норм права законодатель использует разные конструкции. В юридической практике возникают проблемы, связанные с неясностью грамматических конструкций в правотворчестве и (или) с пониманием корректных грамматических конструкций правоприменителями.

Отсюда целью юридической науки является анализ грамматических конструкций, необходимых для ясного определения содержания норм права и определения правил их применения при решении конкретных дел.

Результаты: представлены модели атрибутивно-номинативных словосочетаний, используемых законодателем для определения фактического состава, и сформулированы правила их применения при реализации норм права.

Ключевые слова: фактический состав, атрибутивно-номинативные словосочетания, лексический уровень, грамматический уровень, лексико-грамматическая конструкция. 
Языку права при рассмотрении проблем юридической техники уделяется большое внимание.

Так, выделяют следующие аспекты его изучения: лингвистические знания в правотворчестве; языковое качество нормативных и иных актов; филологические приемы толкования права; правовая (судебная) риторика; лингвистическая экспертиза; речевая культура [6].

Развивая достижения российских ученых Е.В. Васьковского [3, с. 236-517], А.А. Ушакова [10], Н.А. Власенко [4] и др., необходимо провести углубленное изучение грамматических конструкций, используемых законодателем, и вопросов их применения в юридической практике.

Любой язык имеет определенное строение или структуру.

Языки делятся на аналитические и синтетические. Синтетический язык содержит способ выражения грамматики в рамках слова, а аналитический - за его пределами. Отнесение языка к аналитическому или синтетическому означает преобладание в нем способов выражения грамматических значений, соответствующих данному строю [6; 8, с. 405].

Аналитические языки - языки, в которых грамматические отношения имеют тенденцию к передаче в основном через синтаксическую связь, то есть через отдельные служебные слова (предлоги, модальные глаголы и т. п.), через фиксированный порядок слов, контекст и/или интонационные вариации, а не через словоизменение с помощью зависимых морфем (окончаний, суффиксов, приставок и т. д.). Пример аналитического языка - английский язык.

В синтетических языках грамматические значения выражаются в пределах самого слова (аффиксация, внутренняя флексия, ударение, супплетивизм). Для выражения отношений между словами в предложении могут быть использованы также элементы аналитического строя (служебные слова, порядок знаменательных слов, интонация). Пример синтетического языка - русский язык.

В языкознании выделяют несколько уровней (ярусов) языка. В рамках данной работы имеют значение два из них.

Первоначальный ярус любого из языков - лексический. Указанный уровень языка сопоставляется со словесным толкованием (по Васьковскому) [3, с. 263-269], а также со стилистическим толкованием (по Ушакову) $[10$, c. 79$]$.

Лексика (от греч. lexis - слово, выражение) определяется как совокупность слов языка, или как словарный состав языка. Термином «лексика» обозначается не только словарный состав языка в целом, то есть совокупность всех лексических единиц данного языка, но и отдельные части (или пласты) словарного состава [8, с. 239].

Грамматика как особый участок системы языка чаще всего определяется как совокупность (либо система) правил, приемов, способов, средств или норм образования грамматических единиц - грамматических форм в широком смысле [8, с. 385].

Грамматический уровень - это те связи, которые существуют между словами. Благодаря ему последние приобретают смысл и значение.

Это следующий уровень взаимосвязи лексических единиц.

Оба уровня, как лексический, так и грамматический, являются основополагающими, позволяющими законодателю облечь в нужную форму определенное значение, смысл нормы прав через синтаксическую связь - построение грамматических единиц в предложение.

Лексическая единица является элементом грамматической структуры.

Лексика или слова для придания смысла норме права выстраиваются в определенную «композицию» или «структуру». Язык имеет готовые структуры для его использования, например, простые и сложные предложения (сложноподчиненные и сложносочиненные), словосочетания слов, атрибутивные словосочетания, деепричастные и причастные обороты и т. п.

Для нас интерес представляет взаимосвязь лексического и грамматического уровней языка, которые тесно связаны друг с другом, и их взаимодействие, которое осуществляется по разным направлениям.

Так, А.А. Ушаков выделял один из наиболее употребляемых видов лексико-грамматических конструкций - словосочетания с ослабленным глаголом и отглагольные суще- 
ствительные («подвергнуть наказанию», «исполнить приговор», «совершить кражу» и т. д.), фразеологические единицы атрибутивноименного характера («кассационная инстанция», «недействительность сделки», «юридическое лицо» и т. д.) [10, с. 249].

Наиболее часто используемая законодателем лексико-грамматическая конструкция атрибутивно-номинативные словосочетания.

$\mathrm{B}$ определении фактических составов ${ }^{1}$ часто необходимо выделить из рода явлений отдельные виды (в определении субъекта, объекта правоотношений, формы деяния и т. д.), к которым относятся или не относятся предписания. Для этого используется, в том числе, и названная конструкция.

Номинативные единицы языка обозначают отдельные предметы, понятия, представления, отношения и т. п. Такими единицами являются слова и словосочетания [8, с. 64]. Атрибутивное словосочетание - это словосочетание, состоящее из главного (определяемого) слова и одного или нескольких определяющих его слов [5].

Из анализа текстов нормативно-правовых актов следует, что атрибутивные словосочетания могут иметь следующие модели:

- сущ. + причастие, N1 + PР, где N1 имя существительное, РP - причастие;

- сущ. + прилагательное, N1 + Adj, где N1 - имя существительное, Adj - имя прилагательное;

- сущ. + предлог + сущ., N1 + pr + N2, где N1, N2 - имена существительные, pr - местоимение.

Грамматическая характеристика главного компонента - существительного - предопределяет атрибутивный характер отношении в любом словосочетании, так как главный компонент всегда является определяемым, а зависимый - определяющим, атрибутом. Существительное, являясь главным (головным, определяемым) компонентом, характеризуется атрибутом (зависимым компонентом), выраженным либо через существительное (иногда с предлогом), либо через причастие, прилагательное.

Атрибутивность - основное синтаксическое значение рассматриваемых словосочетании - непосредственно заложено в самой форме словосочетания и определяется вне зави- симости от лексического содержания ее компонентов или контекста.

Для выделения отдельного вида из рода правовых явлений необходимо связывать воедино как предмет, понятие (номинатив), так и его характеристику (атрибут), поэтому наиболее точным термином грамматической конструкции в указанных целях будет термин «атрибутивно-номинативные словосочетания».

Как правило, простые атрибутивно-номинативные словосочетания не вызывают трудностей у правоприменителей. При сложных атрибутивно-номинативных словосочетаниях трудностей возникает множество.

Например, ч. 4 ст. 146 ЖК РФ предусматривает: «Решения общего собрания членов товарищества собственников жилья по вопросам, отнесенным настоящим Кодексом к компетенции общего собрания в соответствии с п. 2, 6 и 7 ч. 2 ст. 145 настоящего Кодекса, принимаются не менее чем двумя третями голосов от общего числа голосов членов товарищества. Решения по остальным вопросам принимаются большинством голосов от общего числа голосов присутствующих на общем собрании членов товарищества или их представителей».

Грамматическая структура отсылочного изложения нормы подпадает под атрибутивно-номинативное словосочетание, выраженное сущ. + причастие, N1 + PP, где N1 имя существительное, РP - причастие.

Поскольку причастие также распространяется ${ }^{2}$, обретая форму причастного оборота, можно говорить о сложном атрибутивнономинативном словосочетании.

Более того, подлежащее - существительное «решение» распространено посредством сложной структуры атрибутива, а именно «решение общего собрания членов товарищества по вопросам»: $\mathrm{N} 1+\mathrm{Adj}+\mathrm{N} 2+\mathrm{N} 3+$ $\mathrm{N} 4+$ pr + N5, где N1, N2, N3, N4, N5 - имена существительные, $\mathrm{Adj}$ - имя прилагательное, pr - предлог.

Итак, основные элементы: существительное «решение» - головной элемент словосочетания в структуре «решение общего собрания членов товарищества по вопросам»: $\mathrm{N} 1+\mathrm{Adj}+\mathrm{N} 2+\mathrm{N} 3+\mathrm{N} 4+\mathrm{pr}+\mathrm{N} 5$, зависимые компоненты - словосочетания «общего собрания членов товарищества по вопросам». Сло- 
восочетание может рассматриваться как в его семантической целостности (смысловой нагрузке), так и в отдельной лексической сочетаемости, когда общий смысл не может быть передан. Для сравнения: «собрание членов»лексическая сочетаемость N1 + N2, где N1 головное звено, N2 - атрибутив к головному звену, семантическая нагрузка очень абстрактна - «собрание чего?», «какое собрание» и т. д., и «собрание членов товарищества по вопросам», где атрибутивно-номинативное сочетание имеет модель $\mathrm{N} 1+\mathrm{N} 2+\mathrm{N} 3+\mathrm{pr}+\mathrm{N} 4$, где $\mathrm{N} 1$ - головное звено, (N2+ N3 + pr + N5) - сложный атрибутив к головному звену, семантическая нагрузка уточнена.

Компоненты, усложняющие структуру простого словосочетания, образуют вместе с головным и зависимым компонентом словосочетания других моделей, которые входят как составляющие в словосочетание и являются по отношению к ним вторичными: сложный атрибутив слова «решение» является вторичным по отношению к головному звену.

Распространяющие компоненты (в данном случае это дополнения, выраженные существительными, и определение «общее», выраженное прилагательным) выступают в функции зависимого члена как к головному, так и к подчиненному компоненту словосочетания.

И распространение, и расширение структуры словосочетания возможно в позиции как головного, так и зависимого компонента, а также одновременно в позиции обоих компонентов. Соответственно варьируются разновидности сложных словосочетании и их структурные модели.

Очевидно, что фактический состав решений, которые «принимаются не менее чем двумя третями голосов от общего числа голосов членов товарищества», не выражен простой моделью атрибутивно-номинативных словосочетаний и имеет распространенную структуру атрибутивно-номинативного словосочетания, поскольку головное звено «решение» по отношению к подчиненному компоненту словосочетания «решение по вопросам», определено через причастный оборот подчиненного слова «по вопросам».

При этом именно определение круга вопросов, по которым принимается решение «не менее чем двумя третями голосов от общего числа голосов членов товарищества», является смысловым центром.

Все указанные распространители выполняют функцию модификаторов ${ }^{3}$ (М) к компонентам N1 «решение» и N5 «по вопросам».

Что касается грамматической структуры, используемой для указания фактического состава «не менее чем двумя третями голосов от общего числа голосов членов товарищества», она также выражена атрибутивнономинативным словосочетанием со следующей моделью $\mathrm{Pr}+\mathrm{Num}$ (числительное) + pr + $\mathrm{Adj}+\mathrm{N} 2+\mathrm{N} 3+\mathrm{N} 4+\mathrm{N} 5$, выполняя функцию модификатора к глаголу «принимаются».

Законодатель для упрощения структуры нормы права не указывает конкретные вопросы в целях исключения нагромождения грамматических конструкций (исключение распространенных синонимических рядов), а использует отсылочную норму, в которой такие условия перечислены.

Текст, излагающий норму права, состоит из двух предложений. Объединение их в одном пункте оправданно: достигается уточнение решения в первом предложении, во втором - такое уточнение исключено, и диспозиция выражена проще - «решение принимается». «Решение» (N1) - головное звено, «по остальным вопросам» $(\mathrm{pr}+\mathrm{Adj}+\mathrm{N} 2)-$ сложный атрибутив к головному звену, семантическая нагрузка очерчена кругом вопросов методом исключения, анализа. То есть законодатель, ограничив круг вопросов, решаемых 2/3 от общего количества голосов, оставшиеся вопросы не конкретизировал, а отнес их к категории «остальных».

При рассмотрении данной нормы права нельзя забывать о тех словосочетаниях, которые по существу выполняют роль модификатора по отношению к слову «вопросы» (п. 2, 6 и 7 ч. 2 ст. 145 ЖК РФ):

«2) принятие решений о реорганизации и ликвидации товарищества, назначение ликвидационной комиссии, утверждение промежуточного и окончательного ликвидационных балансов; $<\ldots>$

6) принятие решения о получении заемных средств, в том числе банковских кредитов;

7) определение направлений использования дохода от хозяйственной деятельности товарищества». 
Таким образом, законодатель достаточно четко выразил фактический состав через сложные атрибутивно-номинативные словосочетания, анализ которых приведен выше, для разделения по существу двух кругов вопросов:

1) разрешаемых квалифицированным большинством $2 / 3$;

2) разрешаемых простым большинством голосов.

Нельзя заподозрить законодателя в изложении данной нормы права в неясном или неточном выражении, однако даже при такой относительно несложной грамматической структуре предложения (отсутствуют сложноподчиненные связи) правоприменение данных норм права вызывает разночтения.

В апелляционном определении Пермского краевого суда от 18.06.2012 г. по делу № 334923 сказано: «По правилам п. 7 ч. 2 ст. 145 и ч. 4 ст. 146 ЖК РФ решение общего собрания членов товарищества собственников жилья по вопросам об определении направлений использования дохода от хозяйственной деятельности товарищества, а также об избрании членов правления товарищества, принимаются квалифицированным (не менее чем две трети) большинством голосов от общего числа голосов членов товарищества».

Пункт 7 ч. 2 ст. 145 и ч. 4 ст. 146 ЖК РФ не предусматривают избрание членов Правления.

Суд не придал значения причастному обороту в тексте ч. 4. ст. 146 ЖК РФ «отнесенным настоящим Кодексом...», то есть не заметил атрибутивно-номинативное словосочетание (существительное + причастие), исчерпывающе определяющее круг вопросов, по которым требуется квалифицированное большинство голосов при решении общего собрания членов ТСЖ.

Однако в другом деле Пермский краевой суд (апелляционное определение от 10.06.2013 г. по делу № 33-5195) отказался от применения приведенных норм права в таком толковании и сделал противоположный вывод.

\section{Выводы}

1. Для выделения отдельного вида из рода правовых явлений законодатель использует грамматические конструкции атрибутив- но-номинативных словосочетаний следующих моделей:

- Существительное + Причастие;

- Существительное + Существительное;

- Существительное + Прилагательное.

2. Правильное понимание атрибутивнономинативных словосочетаний зависит от степени их сложности. Излишне введенное количество атрибутов (атрибутивных словосочетаний) вызывает сложность в понимании и приводит к неоднозначному толкованию и нарушению единообразной правоприменительной практики.

3. Правоприменитель должен обращать внимание на наличие атрибутивно-номинативных словосочетаний и при наличии их в тексте нормы права ему необходимо определить цель законодателя. Для реализации цели законодателя (правильного правоприменения) он должен уметь выделить главный компонент, атрибутив, модификатор, степень распространенности атрибутивно-номинативных словосочетаний.

\section{ПРИМЕЧАНИЯ}

${ }^{1}$ Под фактическим составом понимается комплекс юридических фактов, в совокупности влекущих правовое последствие - возникновение, изменение и прекращение правоотношения [7].

2 Предложения, в которых кроме главных членов предложения есть второстепенные, называются распространенными [2].

3 «Распростанители выполняют функцию модификаторов» [5, с. 126]. «Modifier n модификатор; определение adverbial обстоятельство (член предложения; также adverbial) sentence член предложения, относящийся ко всему предложению (также adjunct) modify v изменять; определять» [1].

\section{СПИСОК ЛИТЕРАТУРЫ}

1. Англо-русский словарь лингвистических терминов / под ред. Д. В. Хворостина. - Челябинск, 2007.- С. 62.

2. Бабайцева, В. В. Русский язык: Теория. 59 кл. : учебник / В. В. Бабайцева, Л. Д. Чеснокова. М. : Дрофа, 2016. - 202 с.

3. Васьковский, Е. В. Теория толкования гражданского права. Очерк методологии цивилистической догматики / Е. В. Васьковский // Избранные работы Польского периода. - М. : Статут, 2016. - 640 с. 
4. Власенко, Н. А. Проблемы точности выражения формы права (лингво-логический анализ) : дис. ... в форме науч. докл. ... д-ра юрид. наук / Власенко Николай Александрович. - Екатеринбург, 1997.

5. Воронина, Е. Н. Атрибутивные словосочетания с предлогом of / Е. Н. Воронина // Вестник КГУ им. Н.А. Некрасова. - 2008. - № 3. - С. 124-130.

6. Давыдова, М. Л. Юридическая техника: проблемы теории и методологии / М. Л. Давыдова. - Волгоград, 2009. -С. 119-120.

7. Исаков, В. Б. Фактический состав в механизме правового регулирования / В. Б. Исаков. Саратов, 1980. - С. 2.

8. Немченко, В. Н. Введение в языкознание / В. Н. Немченко. - М. : Дрофа, 2008. - 703 с.

9. Решетникова, Н. Д. Языки аналитические и синтетические / Н. Д. Решетникова, А. О. Савинова // Молодой ученый. - 2013. - № 12. - С. 873-877.

10. Ушаков, А. А. Очерки советской законодательной стилистики. Право и язык / А. А. Ушаков. М. : Российская академия правосудия, 2008. -314 с.

\section{REFERENCES}

1. Khvorostin D.V. Anglo-russkiy slovar lingvisticheskikh terminov [English-Russian Dictionary of Linguistic Terms]. Chelyabinsk, 2007.62 p.

2. Babaytseva V.V. Russkiy yazyk: Teoriya. 59 kl.: uchebnik [Russian Language: Theory. 59 Grades. Textbook]. Moscow, Drofa Publ., 2016. 202 p.

3. Vaskovskiy E.V. Teoriya tolkovaniya grazhdanskogo prava. Ocherk metodologii tsivilisticheskoy dogmatiki [Theory of the Interpretation of Civil Law. Essay on the Methodology of Civilistic Dogmatics]. Izbrannye raboty Polskogo perioda [Selected Works of the Polish Period]. Moscow, Statut Publ., 2016. 640 p.

4. Vlasenko N.A. Problemy tochnosti vyrazheniya formy prava (lingvo-logicheskiy analiz): dis. ...d-ra yurid. nauk [Problems of the Accuracy of Expressing the Form of Law: Linguistic-Logical Analysis. Dr. jurid. sci. diss.]. Ekaterinburg, 1997.

5. Voronina E.N. Atributivnye slovosochetaniya s predlogom of [Attributive Word Combinations with the Preposition “of']. Vestnik KGU im. Nekrasova, 2008, no. 3, pp. 124-130.

6. Davydova M.L. Yuridicheskaya tekhnika: problemy teorii $i$ metodologii [Legal Technology: Problems of Theory and Methodology]. Volgograd, 2009, pp. 119-120.

7. Isakov V.B. Fakticheskiy sostav v mekhanizme pravovogo regulirovaniya [Composition of Facts in the Mechanism of Legal Regulation]. Saratov, Izd-vo Sarat. un-ta, 1980, p. 2

8. Nemchenko V.N. Vvedenie v yazykoznanie [Introduction to Linguistics]. Moscow, Drofa Publ., 2008. 703 p.

9. Reshetnikova N.D., Savinova A.O. Yazyki analiticheskie i sinteticheskie [Analytical and Synthetic Languages]. Molodoy uhenyy, 2013, no. 12, pp. 873-877.

10. Ushakov A.A. Ocherki sovetskoy zakonodatelnoy stilistiki. Pravo i yazyk [Essays on Soviet Legislative Stylistics. Law and Language]. Moscow, Rossiyskaya akademiya pravosudiya Publ., 2008.314 p.

\section{Information about the Authors}

Sergey B. Polyakov, Doctor of Juridical Sciences, Associate Professor, Professor of the Department of the Theory and History of State and Law, Perm State National Research University, Genkelya St., 14, 614990 Perm, Russian Federation, psb59@rambler.ru.

Anastasia V. Bogdanova, Candidate for a Master's Degree, Department of the Theory and History of State and Law, Perm State National Research University, Genkelya St., 14, 614990 Perm, Russian Federation, anastassy@yandex.ru.

\section{Информация об авторах}

Сергей Борисович Поляков, доктор юридических наук, доцент, профессор кафедры теории и истории государства и права, Пермский государственный научно-исследовательский университет, ул. Генкеля, 14, 614990 г. Пермь, Российская Федерация, psb59@rambler.ru.

Анастасия Владиславовна Богданова, магистрант кафедры теории и истории государства и права, Пермский государственный научно-исследовательский университет, ул. Генкеля, 14, 614990 г. Пермь, Российская Федерация, anastassy@yandex.ru. 